\title{
Lip and Oral Cavity Cancer pT3 TNM Finding v8
}

National Cancer Institute

\section{Source}

National Cancer Institute. Lip and Oral Cavity Cancer pT3 TNM Finding v8. NCI

Thesaurus. Code C132697.

Lip and oral cavity cancer with tumor size greater than $4 \mathrm{~cm}$ or any tumor greater than 10 mm DOI. (from AJCC 8th Ed.) 